\title{
Bibliometric Analysis on the Trend of the Computed Tomography (CT)-Related Studies in the Field of Forensic Science
}

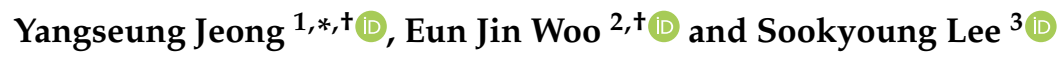 \\ 1 Department of Biology, Middle Tennessee State University, Murfreesboro, TN 37132, USA \\ 2 Department of History, Sejong University, Seoul 05006, Korea; redqin@sejong.ac.kr \\ 3 Division of Forensic Medical Examination, National Forensic Service, Wonju 26460, Korea; heart@korea.kr \\ * Correspondence: yangseung.jeong@mtsu.edu; Tel.: +1-615-898-5615 \\ + These authors contributed to the manuscript equally as the first authors.
}

Received: 8 October 2020; Accepted: 16 November 2020; Published: 17 November 2020

check for updates

\begin{abstract}
The computed tomography (CT) technique has attracted much attention as a promising tool for non-invasive diagnosis and examination in the field of forensic science. The purpose of this study is to assess the trend in CT-related forensic studies through bibliometric methods and thus present a holistic idea about the application of CT in the field of forensic science of the past and present. A total of 2084 articles published in the Scopus index journals between 1978 and 2020 were analyzed using VOSviewer 1.6.15. A drastic increase in the number of CT-related articles was noticed in forensic science since the early 2000s. Switzerland, having the most productive institution (University of Zurich) and author (Michael J. Thali), contributed most to the increasing number of publications. Forensic Science International was the top journal, where approximately $12.5 \%$ of the articles (261 out of 2084) have been published. CT was frequently used for autopsy and diagnosis purposes, but recently its applicability has expanded to the field of forensic anthropology and personal identification. This research is expected to provide researchers using CT with not only an understanding about past research trends but also an insight about future research topics and potential collaborative opportunities.
\end{abstract}

Keywords: bibliometric analysis; computed tomography; forensic science; Scopus; VOSviewer

\section{Introduction}

There has long been an effort to devise non-invasive diagnostic techniques in the fields of medical and forensic sciences. The radiographs introduced by Conrad Roentgen in 1895 have opened the era of forensic radiology since the first postmortem radiographic examination in 1898 [1]. With the development of three-dimensional imaging techniques such as magnetic resonance imaging (MRI) and computed tomography (CT) in the late 20th century, forensic imaging has attracted much attention as a new non-invasive diagnostic tool as well as a new subfield of forensic science [2,3]. Compared to the radiographs, forensic imaging using cross-sectional techniques has advantages in that it allows for three-dimensional examination and visualization of complex structures in an easy and interactive way $[1,4]$. Indeed, the past two decades have seen a drastic development of CT techniques and subsequently a rapid growth in the application of CT in the forensic context [5].

The purpose of this study is to quantitatively assess the trend of CT-related forensic studies through bibliometric methods and thus present a holistic idea about the application of CT in the field of forensic science of the past and present. Bibliometric studies allow to track the frequencies and trends of scientific publications associated with a specific field/topic and the relationship of citations 
between the works in a systematic way [6,7]. Specific focus will be placed on the growth trend of this field in terms of the number of publications, most active journals with trend topics, and productive authors and countries. This research is expected to provide researchers using CT with not only an understanding about the past research trend but also an insight about future research topics and potential collaborative partners.

\section{Materials and Methods}

The Scopus indexed articles were searched using the Document Search function [8] on 4 November 2020. Four terms-“"forensic" OR “medicolegal" OR "legal medicine" AND “computed tomography"-were used for document search so that any articles containing one of the three pairs of keywords (i.e., "forensic—computed tomography", "medicolegal—computed tomography", or "legal medicine-computed tomography") in their title, abstract, and/or keywords could be detected. Document type was limited to "Articles and Reviews" so other types of publications such as book chapters, letters, conference papers, and surveys were excluded. The years of publication were not specified, and Ostertag et al.'s [9] work titled "Diagnostic possibilities of computerized tomography in forensic examination of cerebral traumatized persons" was marked as the earliest article. The citation information (e.g., authors, title, publication year, citation counts, and source), bibliographic information (e.g., affiliations and correspondence address), abstract and keywords, and reference information of all selected articles were exported in a comma-separated values (CSV) file format for further analyses. Informed consent was not required from the authors of the articles because the data were collected as secondary data lacking personal information.

Microsoft Excel was used to calculate descriptive statistics and annual growth rate (AGR) and to produce related plots. AGRs were calculated as follows, which represents the percentage rate of positive or negative growth of a product in a certain year compared to the previous year [10].

$$
A G R_{i}=\frac{N_{i}-N_{i-1}}{N_{i-1}} \times 100
$$

where $N_{i}$ : number of documents in the year $i$.

In calculating AGRs, only the articles published between 2000 and 2019 were included, during which drastic increase in publications was observed. The publications in 2020 were excluded from the AGR calculation because the number of publications at the time of data collection for this study could not represent that of the entire year.

VOSviewer 1.6.15 [11] was used for bibliometric analysis. VOSviewer is an open source computer program which makes it possible to perform bibliometric analyses and display two-dimensional maps based on the co-occurrences of the nodes/subjects [12]. One of the advantages of using VOSviewer for this purpose is that VOSviewer can analyze the bibliometric data exported from the major journal archives such as Scopus, Web of Science, and PubMed directly.

\section{Results}

\subsection{Annual Trend of Publications}

Per the ScopusS document search, a total of 2084 CT-related articles have been published in the forensic field since the 1970s (Table 1). The numbers of published articles per year were below ten until 2002 and the sum of publications between 1978 and 2002 constitutes only $3.7 \%$ of the total publications (78 out of 2084). However, from the early 2000s, a drastic increase in the number of publications is noticed (Table 1 and Figure 1a). Since 2001, each year set a new record in the number of annual publications except for 2005, 2014, and 2018. More than 100 articles have been published every year since 2012; and 2017 was the first year during which more than 200 articles were published. The first quartile (25\%) in the number of publications was reached in 2012. Yet, it took only three years for the second and third quartiles to be reached (2015 and 2018, respectively). Figure $1 \mathrm{~b}$ shows a fluctuating 
trend in AGR. The AGR indicates a relative growth of publications within a year compared to the previous year. For example, a positive AGR indicates that the number of publications in a certain year exceeded that of the previous year, and vice versa. Since 2000, there were three years with negative ARG's (-42.9\% in 2001, $-5.0 \%$ in 2005, $-3.5 \%$ in 2018) (Table 1 and Figure $1 \mathrm{~b})$. However, the differences in numbers of publications between those years and their preceding years were minimal (three in 2001-2000; one in 2005-2004; and seven in 2014-2013).

Table 1. The number and annual growth rate (AGR) of CT (computed tomography) -related articles in the Forensic section of Scopus between 1978 and 2020.

\begin{tabular}{|c|c|c|c|}
\hline Publication Year * & Number of Documents & Cumulative Total & Annual Growth Rate (\%) ** \\
\hline 1978 & 1 & 1 & \\
\hline 1980 & 1 & 2 & \\
\hline 1981 & 1 & 3 & \\
\hline 1982 & 3 & 6 & \\
\hline 1983 & 1 & 7 & \\
\hline 1985 & 8 & 15 & \\
\hline 1986 & 4 & 19 & \\
\hline 1988 & 1 & 20 & \\
\hline 1989 & 1 & 21 & \\
\hline 1990 & 1 & 22 & \\
\hline 1992 & 2 & 24 & \\
\hline 1993 & 2 & 26 & \\
\hline 1994 & 6 & 32 & \\
\hline 1995 & 5 & 37 & \\
\hline 1996 & 6 & 43 & \\
\hline 1997 & 6 & 49 & \\
\hline 1998 & 7 & 56 & \\
\hline 1999 & 3 & 59 & \\
\hline 2000 & 7 & 66 & 100.0 \\
\hline 2001 & 4 & 70 & -42.9 \\
\hline 2002 & 8 & 78 & 100.0 \\
\hline 2003 & 11 & 89 & 37.5 \\
\hline 2004 & 20 & 109 & 81.8 \\
\hline 2005 & 19 & 128 & -5.0 \\
\hline 2006 & 37 & 165 & 94.7 \\
\hline 2007 & 44 & 209 & 18.9 \\
\hline 2008 & 51 & 260 & 15.9 \\
\hline 2009 & 56 & 316 & 9.8 \\
\hline 2010 & 66 & 382 & 17.9 \\
\hline 2011 & 80 & 462 & 21.2 \\
\hline 2012 & 107 & 569 & 33.8 \\
\hline 2013 & 151 & 720 & 41.1 \\
\hline 2014 & 151 & 871 & 0.0 \\
\hline 2015 & 181 & 1052 & 19.9 \\
\hline 2016 & 185 & 1237 & 2.2 \\
\hline 2017 & 202 & 1439 & 9.2 \\
\hline 2018 & 195 & 1634 & -3.5 \\
\hline 2019 & 239 & 1873 & 22.6 \\
\hline 2020 & 211 & 2084 & \\
\hline Total & 2084 & & \\
\hline
\end{tabular}

*Years with no publications are not presented; ** Only the AGRs between 2000 and 2019 are presented. 


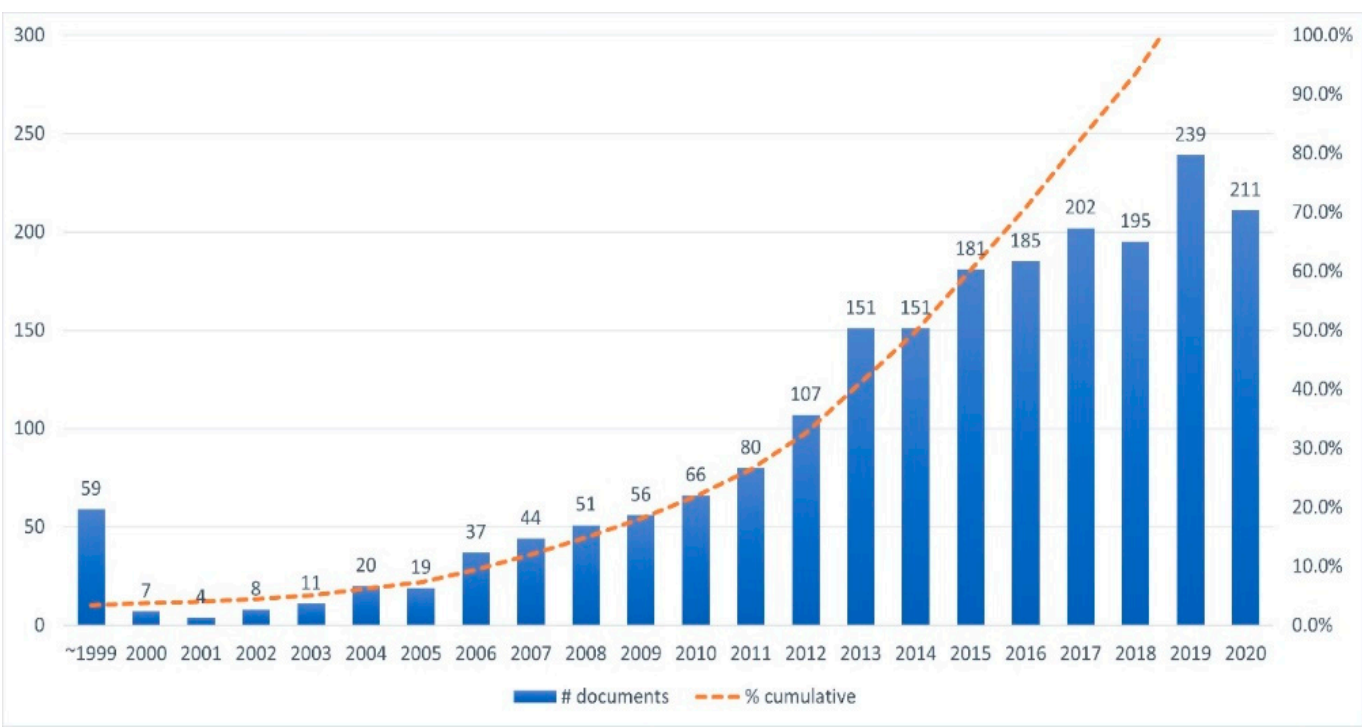

(a)

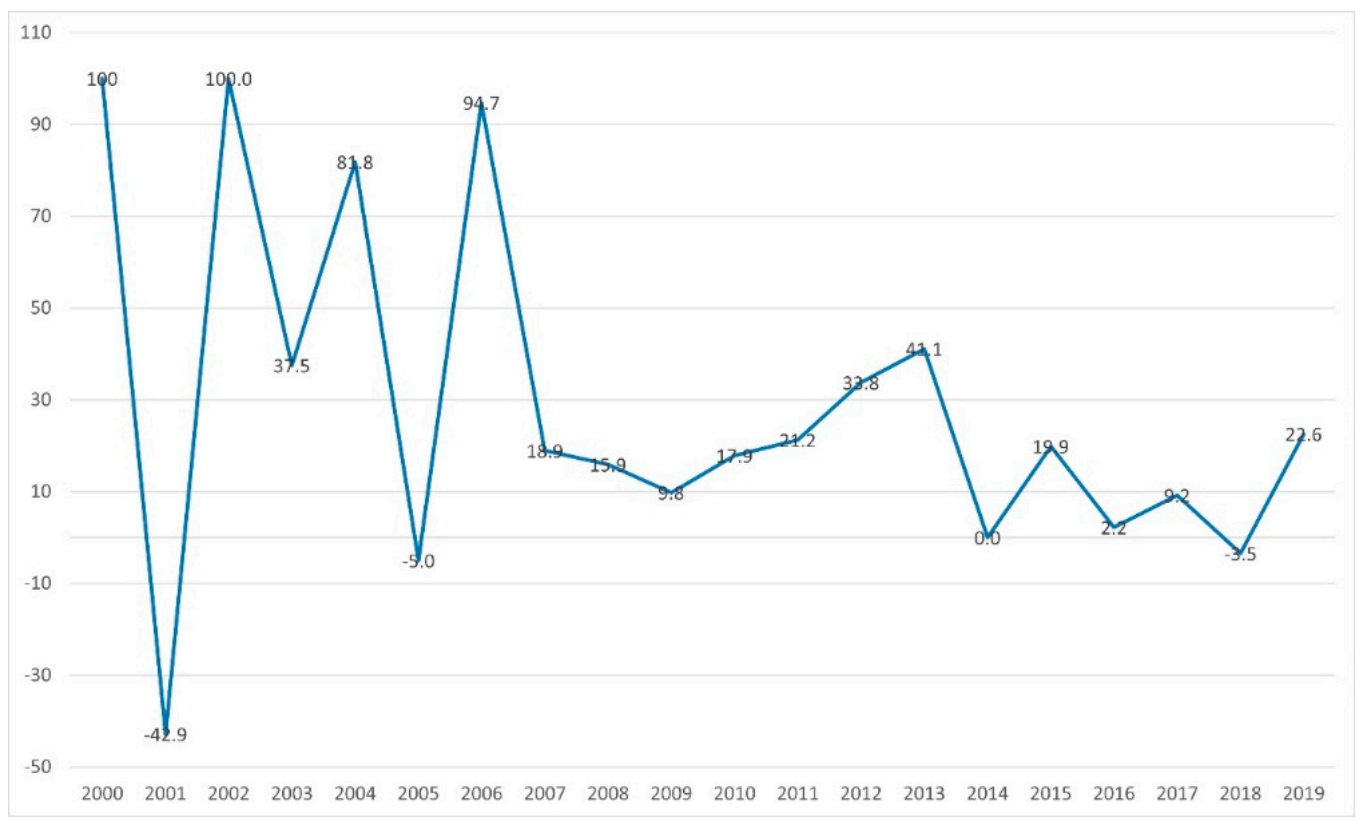

(b)

Figure 1. Number of annual publications (a) and annual growth rate (AGR) of the publications (b). The positive and negative values of AGR indicate that the number of publications within a year was greater or less than the previous year, respectively.

\subsection{Productive Countries}

CT-related forensic studies have been conducted by the authors from 104 countries. Table 2 and Figure 2 show top 16 countries that have produced 40 or more articles. Switzerland was the most productive country in terms of the number of publications $(n=335)$ as well as the number of citations $(n=6662)$ followed by United States $(\#$ articles = 259; \# citations $=4775)$. 
Table 2. Countries that have published 40 or more CT-related articles in the Forensic section of Scopus between 1978 and 2020.

\begin{tabular}{ccc}
\hline Country & Number of Documents & Number of Citations \\
\hline Switzerland & 335 & 6662 \\
United States & 259 & 4775 \\
Japan & 224 & 2278 \\
Germany & 207 & 3534 \\
United Kingdom & 186 & 2719 \\
Italy & 173 & 2005 \\
France & 144 & 1625 \\
Australia & 106 & 1692 \\
China & 90 & 393 \\
Turkey & 79 & 686 \\
India & 71 & 381 \\
Brazil & 51 & 308 \\
The Netherlands & 47 & 396 \\
Denmark & 45 & 522 \\
Malaysia & 42 & 174 \\
Egypt & 40 & 253 \\
\hline
\end{tabular}

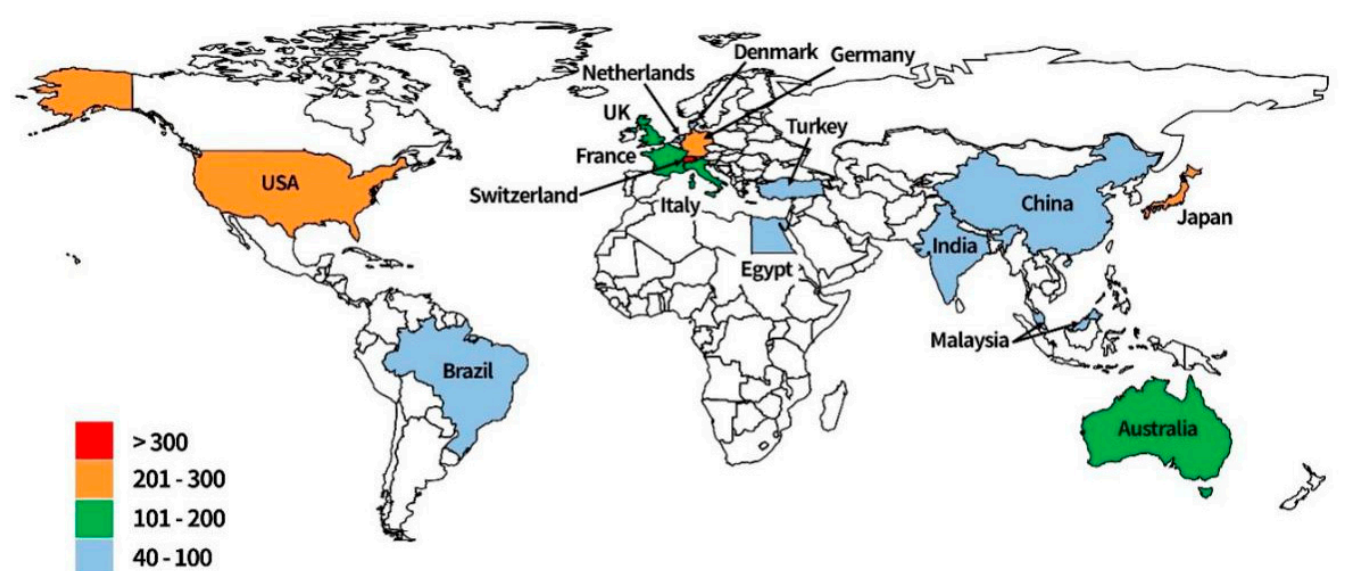

Figure 2. Color map showing the countries that have published 40 or more CT-related articles in the Forensic section of Scopus between 1978 and 2020.

The co-authorship analysis shows that Switzerland, the United States, the United Kingdom, Italy, and Germany were the top 5 countries in terms of the collaborative network (Figure 3). The size of the circles and thickness of the lines in Figure 3 indicate the total link strength of a country and the strength of network between two countries, respectively. Based on the strength and pattern of the network, four clusters could be found out of 16 countries: (i) Australia, Brazil, Denmark, The Netherlands, the United Kingdom, and the United States, (ii) Egypt, India, Japan, Malaysia, and Turkey, (iii) Germany, Italy, and Switzerland, and (iv) China and France. 


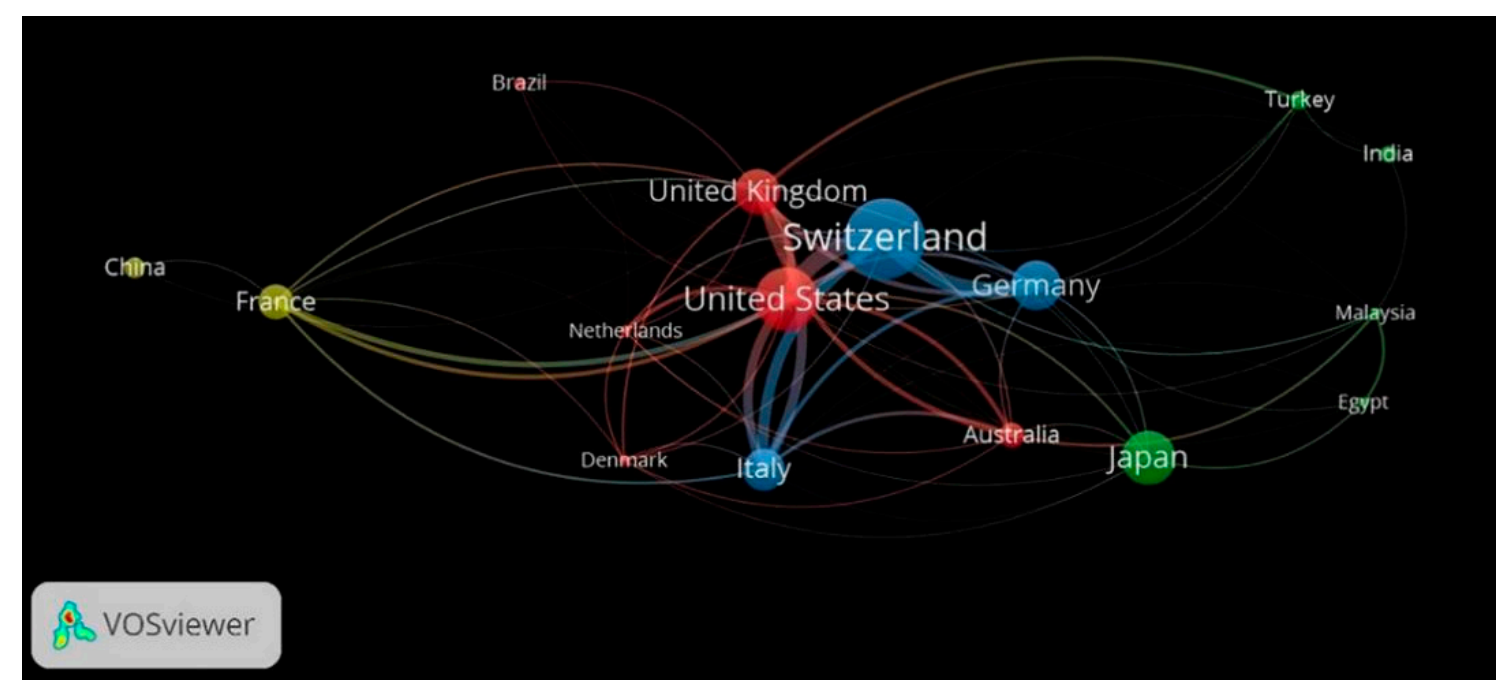

Figure 3. Network visualization map showing the collaborative relations among top 16 countries. The size of circles and fonts denotes the total link strength of the frequency of collaborations; the thickness of lines indicates the strength of collaborations between two countries; and the color indicates the clusters of collaborations.

\subsection{Productive Institutions and Authors}

A total of 5929 authors from 5194 institutions have contributed to CT-related forensic studies. Tables 3 and 4 list the authors and institutions that have published 30 or more articles. Among the 27 authors in Table 4, Michael J. Thali is the only one who authored more than 100 articles. Among the 16 institutions that produced 30 or more articles, six institutions are located in Switzerland; two in Australia, France, Japan, and the United Kingdom; and one in China and Germany. It was also noted that all the top three institutions-University of Zurich (\# articles = 159), University of Bern (\# articles = 136), and UniversitätsSpital Bern (\# articles $=87$ ) —are located in Switzerland.

Table 3. Authors who have published 30 or more CT-related articles in the Forensic section of Scopus between 1978 and 2020.

\begin{tabular}{cccccc}
\hline Author & $\begin{array}{c}\text { Number of } \\
\text { Occurrence }\end{array}$ & $\begin{array}{c}\text { Number of } \\
\text { Citations }\end{array}$ & Author & $\begin{array}{c}\text { Number of } \\
\text { Occurrence }\end{array}$ & $\begin{array}{c}\text { Number of } \\
\text { Citations }\end{array}$ \\
\hline Thali M.J. & 180 & 4453 & Dirnhofer R. & 43 & 2633 \\
Iwase H. & 61 & 631 & Dedouit F. & 41 & 599 \\
Ampanozi G. & 60 & 663 & Motomura A. & 41 & 356 \\
Gascho D. & 57 & 382 & Rutty G.N. & 41 & 933 \\
Makino Y. & 57 & 500 & Thali M. & 40 & 888 \\
Jackowski C. & 55 & 2364 & Torimitsu S. & 40 & 335 \\
Schweitzer W. & 53 & 770 & Morgan B. & 37 & 890 \\
Flach P.M. & 49 & 505 & Bolliger S.A. & 35 & 677 \\
Telmon N. & 49 & 698 & Yen K. & 33 & 1497 \\
Grabherr S. & 48 & 928 & Aghayev E. & 30 & 1404 \\
Ruder T.D. & 46 & 766 & Hatch G.M. & 30 & 498 \\
Inokuchi G. & 45 & 390 & Ross S. & 30 & 985 \\
Yajima D. & 44 & 530 & Verhoff M.A. & 30 & 444 \\
Chiba F. & 44 & 348 & & & \\
\hline
\end{tabular}


Table 4. Institutions that have produced 30 or more CT-related articles in the Forensic section of Scopus between 1978 and 2020.

\begin{tabular}{ccc}
\hline Institution & Number of Documents & Country \\
\hline University of Zurich & 159 & Switzerland \\
University of Bern & 136 & Switzerland \\
UniversitätsSpital Bern & 87 & Switzerland \\
Chiba University & 59 & Japan \\
Victorian Institute of Forensic Medicine & 50 & Australia \\
University of Tokyo & 46 & Japan \\
Hopital de Rangueil & 46 & France \\
UniversitätsSpital Zurich & 45 & Switzerland \\
Monash University & 44 & Australia \\
Medizinische Fakultät & 40 & Germany \\
University of Leicester & 40 & United Kingdom \\
Leicester Royal Infirmary & 39 & United Kingdom \\
Université de Lausanne UNIL & 38 & Switzerland \\
Aniversitätsklinikum Hamburg-Eppendorf und & 35 & France \\
Centre Hospitalier Universitaire Vaudois & 31 & Switzerland \\
Ministry of Justice, China & 31 & China \\
\hline
\end{tabular}

\subsection{Leading Journals}

Out of 408 journals selected by the Scopus search, only 23 journals have published ten or more CT-related forensic studies (Table 5). Forensic Science International is ranked as the most active journal in terms of the number of publications $(n=261)$ as well as the number of citations $(n=5241)$, which is followed by the International Journal of Legal Medicine (\# articles = 200; \# citations = 3424).

Table 5. Journals that have published ten or more CT-related articles in the Forensic section of Scopus between 1978 and 2020.

\begin{tabular}{ccc}
\hline Journal & Number of Documents & Number of Citations \\
\hline Forensic Science International & 261 & 5241 \\
International Journal of Legal Medicine & 200 & 3424 \\
Journal of Forensic Radiology and Imaging & 156 & 876 \\
Journal of Forensic Sciences & 146 & 2865 \\
Legal Medicine & 146 & 1430 \\
Forensic Science, Medicine, and Pathology & 98 & 1122 \\
Journal of Forensic and Legal Medicine & 65 & 621 \\
American Journal of Forensic Medicine and Pathology & 58 & 670 \\
Rechtsmedizin & 43 & 207 \\
Indian Journal of Forensic Medicine and Toxicology & 37 & 1 \\
Journal of Forensic Medicine & 30 & 24 \\
Romanian Journal of Legal Medicine & 29 & 55 \\
Radiologia Medica & 25 & 337 \\
Australian Journal of Forensic Sciences & 24 & 48 \\
Forensic Imaging & 24 & 10 \\
Academic Forensic Pathology & 19 & 32 \\
Egyptian Journal of Forensic Sciences & 15 & 80 \\
European Radiology & 12 & 620 \\
Medicine, Science, and the Law & 12 & 52 \\
Plos One & 12 & 78 \\
Revue de Medecine Legale & 12 & 9 \\
American Journal of Physical Anthropology & 10 & 142 \\
Seminars in Ultrasound, CT, and MRI & 10 & 83
\end{tabular}


Figure 4 displays the citation network among the top ten journals where 30 or more articles have been published. The size of the circles in Figure 4 denotes the total link strength (i.e., the relative frequency of a journal's citations by other journals). Obviously, the articles published in Forensic Science International have been most frequently cited by most of the other journals. It was also noted that the Journal of Forensic Radiology and Imaging, one of the young journals with its first issue published in 2013, ranked third and sixth in the number of publications and citations, respectively (Table 5). Based on the frequency and pattern of citations among the top ten journals, four clusters could be found: [i] Am J Forensic Med Pathol, Forensic Sci Int, Indian J Med Forensic Med Toxicol, J Forensic Legal Med, J Forensic Sci, [ii] Forensic Sci Med Pathol, J Forensic Radiol Imaging, [iii] Int J Legal Med, Rechtsmedizin, and [iv] Legal Med.

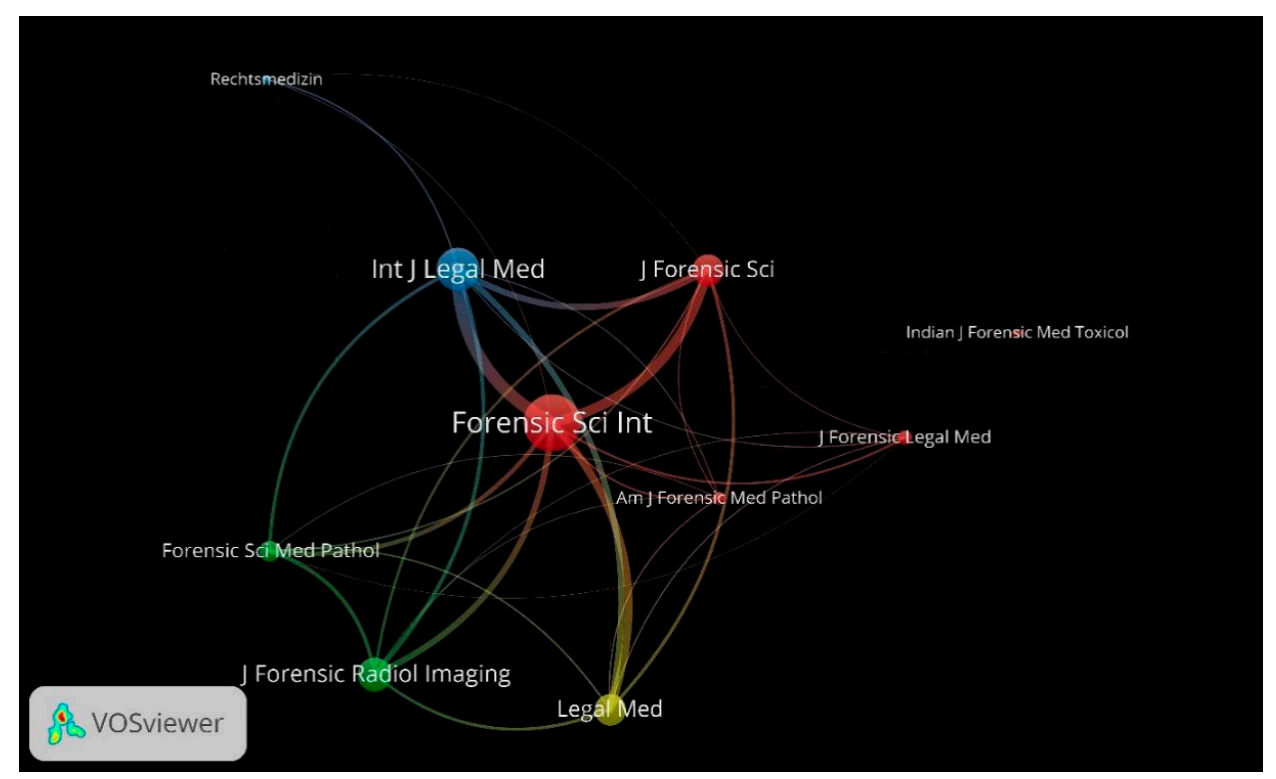

Figure 4. Network visualization map of citation analysis among top ten journals. The size of circles and fonts denotes the total number of documents published in the journals; the thickness of lines indicates the relative frequency of citations between two journals; and the color indicates the clusters of journals.

\subsection{Keywords}

Out of 3998 keywords, there were 27 keywords that have appeared 30 or more times in the CT-related forensic studies (Table 6). Based on the strength and pattern of co-occurrence/link of the keywords, four clusters could be found (Table 6). The keywords in the same cluster tended to occur together in the articles. The result of the co-occurrence test is displayed on the map in Figure 5, where the size of circles and the thickness of lines denote the relative number of publications and the relative frequency of co-occurrence between two keywords, respectively. When the time of publication is taken into account, it was noted that the keywords colored in yellow such as "Forensic Anthropology", "Postmortem CT", “Cone Beam CT", and "Micro CT" have appeared relatively recently.

Table 6. Keywords that have appeared in 30 or more CT-related articles in the Forensic section of Scopus between 1978 and 2020. The keywords in the same cluster tended to have appeared together.

\begin{tabular}{cccc}
\hline Keyword & $\begin{array}{c}\text { Number of } \\
\text { Occurrence }\end{array}$ & $\begin{array}{c}\text { Total Link } \\
\text { Strength }\end{array}$ & Cluster \\
\hline $\begin{array}{c}\text { Computed Tomography/CT } \\
\text { Postmortem Computed Tomography/Postmortem CT/PMCT }\end{array}$ & 420 & 544 & 2 \\
Forensic Anthropology & 293 & 338 & 3 \\
Forensic Radiology & 245 & 318 & 1 \\
Forensic Science & 215 & 358 & 3 \\
\hline
\end{tabular}


Table 6. Cont

\begin{tabular}{cccc}
\hline Keyword & $\begin{array}{c}\text { Number of } \\
\text { Occurrence }\end{array}$ & $\begin{array}{c}\text { Total Link } \\
\text { Strength }\end{array}$ & Cluster \\
\hline Virtopsy/Virtual Autopsy & 195 & 338 & 3 \\
Autopsy & 162 & 220 & 2 \\
Forensic Pathology & 123 & 167 & 2 \\
Cone Beam CT & 82 & 103 & 1 \\
Age Estimation & 81 & 121 & 1 \\
Sex Estimation/Sex Determination & 79 & 126 & 1 \\
Forensic Imaging & 66 & 98 & 3 \\
Forensic Medicine & 62 & 59 & 2 \\
Forensic & 59 & 66 & 2 \\
Magnetic Resonance Imaging & 54 & 93 & 3 \\
Postmortem Imaging & 53 & 106 & 3 \\
Identification & 50 & 79 & 1 \\
Forensic Anthropology Population Data & 49 & 59 & 1 \\
Sexual Dimorphism & 44 & 72 & 1 \\
Radiology & 42 & 74 & 2 \\
Forensic Dentistry & 37 & 50 & 1 \\
Postmortem & 36 & 69 & 2 \\
Micro CT & 36 & 28 & 4 \\
Multidetector CT & 34 & 42 & 1 \\
CT Scan & 34 & 24 & 2 \\
Forensic Odontology & 32 & 55 & 1 \\
Forensic Autopsy & 30 & 26 & 3 \\
\hline
\end{tabular}

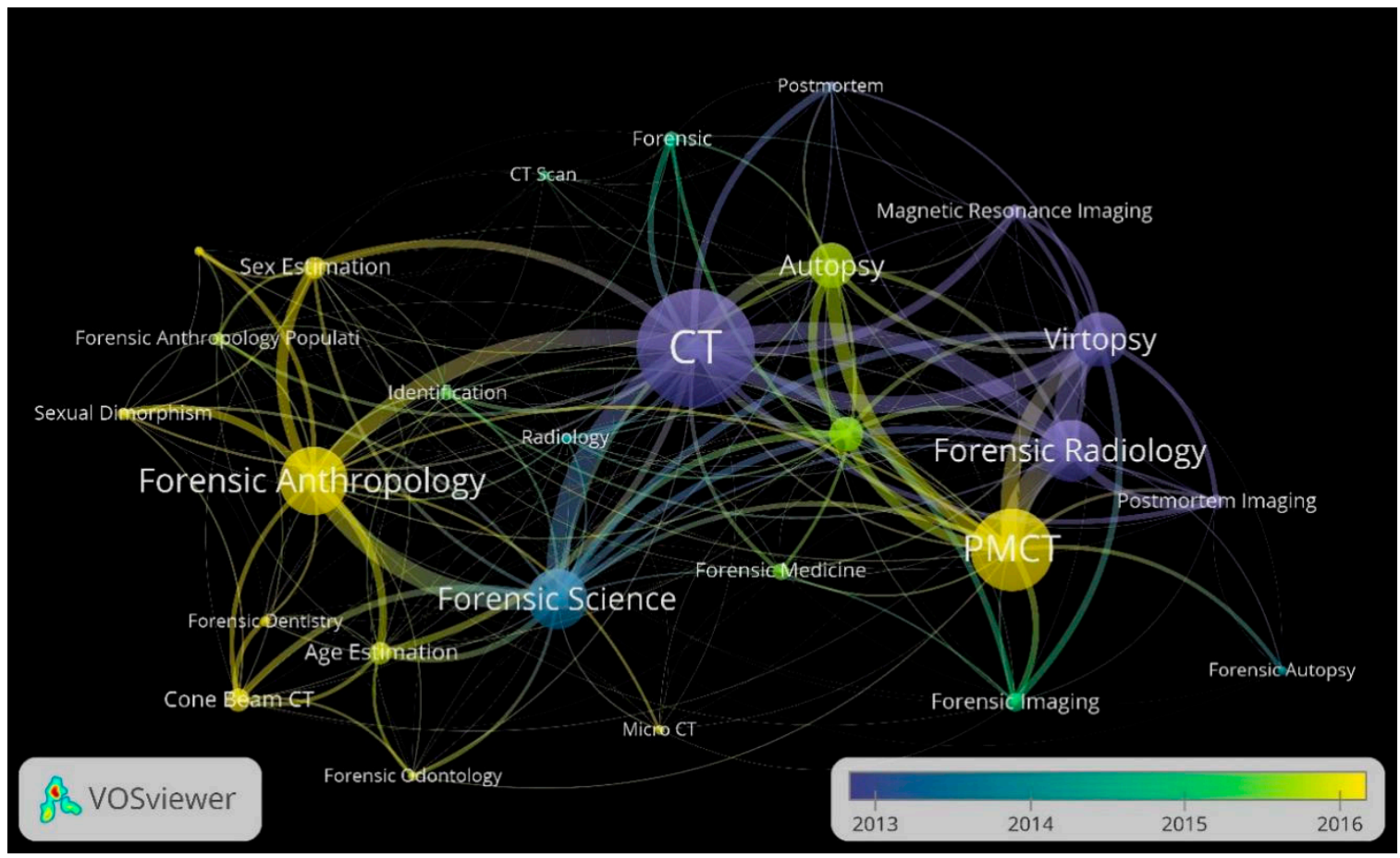

Figure 5. Overlay visualization map of co-occurrence analysis among top 27 keywords. The size of circles and fonts denotes the relative number of documents; the thickness of lines indicates the relative frequency of co-occurrence between two keywords; and the color indicates the clusters of journals. The number of frequencies of the keywords has increased from purple to yellow (purple-blue-green-yellow). 


\section{Discussion}

Bibliometric analysis allows for a quantitative, systematic, and objective assessment on the publications in a field, which helps researchers to have an understanding about the past and current state of the field as well as a holistic insight on its future direction $[6,7,10]$. Among the earliest topics for the bibliometric analyses was forensic science where the publications of diverse subdisciplines of forensic science in Europe were examined [13,14]. The establishment of digital journal archives (e.g., Scopus, Web of Science, and PubMed) and development of computer software that can analyze the archived data (e.g., VOSviewer) makes the process of bibliometric analysis straightforward and time-efficient. Thus, recent years have seen increasing bibliometric analyses in various fields, e.g., $[6,7,15,16]$.

One of the notable findings in the current study is the rapid increase in the number of articles, particularly since the early 2000s (Table 1). In 2003, Thali and colleagues [4] emphasized and encouraged the utility of imaging techniques such as CT and MRI in the field of forensic science. Interestingly, this year was the first year during which more than ten CT-related forensic articles were published $(n=11)$, and the increasing trend has continued except for 2005, 2014, and 2018. The AGR has fluctuated between 2000 and 2019; however, except for 2001, 2005, and 2018, there were no years with negative AGRs. In other words, the number of publications for most of the past 20 years exceeded (or was the same as) that of the preceding year (Table 1). In 2017, the number of annual publications exceeded 200 for the first time $(n=202)$ and the increasing trend is likely to continue in 2020 as well $(n=211$ as of 4 November 2020).

Switzerland and United States ranked first and second in both the number of publications ( $n=335$ and $n=259$, respectively) and citations ( $n=6662$ and $n=4775$, respectively) (Table 2). Japan ranked third in the number of publications $(n=224)$, but Germany ranked third in terms of the number of citations $(n=3534)$. Cluster analysis in Figure 3 shows which countries have close collaborative relationships. Demir et al. [6] state that geographic location is an important factor in terms of collaborations between countries. However, the result of the current study did not show a clear relationship between the geographic locations and collaborative network of the countries. For example, eight European countries in Figure 3 were divided into four different clusters, and China and France were in the same cluster. It is beyond the scope of the current study to investigate the underlying factors affecting the international collaborations, but it would be a significant topic for future research.

The leading role of Switzerland in the CT-related forensic studies was also evident in the list of most productive institutions (Table 4). Six out of 16 institutions in Table 4, including the top three institutions, are located in Switzerland. Moreover, approximately $23.8 \%$ of the articles (496 out of 2084) have been produced by these six Swiss institutions. The rest of the institutions are located in Australia, China, France, Germany, Japan, and the United Kingdom. Interestingly, any institutions from the United States or Italy, which ranked second and sixth in the number of publications, were not listed in Table 4. This is possibly because the large number of publications in the United States $(n=259)$ and Italy $(n=173)$ have been produced by diverse research groups rather than by a small number of leading groups.

Approximately $43.6 \%$ of the CT-related forensic studies (909 out of 2084 articles) have been published in five journals (Forensic Science International, International Journal of Legal Medicine, Journal of Forensic Radiology and Imaging, Journal of Forensic Sciences, and Legal Medicine) with the total number of citations of 13,836 (Table 5). Forensic Science International ranked first in both the number of publications $(n=261)$ and number of citations $(n=5241)$. Indeed, the co-citation analysis map in Figure 4 displays the Forensic Science International in the center, which indicates that the articles in the journal have been cited by most of the other journals. Similar results were obtained from previous bibliometric studies in the fields of legal medicine [6] and forensic anthropology [16], where Forensic Science International was listed as the most influential journal.

The keyword analysis revealed four clusters, of which centers (i.e., the keywords with the greatest total link strength of each cluster) were "Forensic Anthropology", "Postmortem Computed 
Tomography", "Autopsy", and "Computed Tomography". This result indicates that CT has been primarily used in two forensic subfields: forensic pathology/medicine and forensic anthropology. Since the development of X-ray CT in 1974, the CT technique has been constantly applied to forensic pathological studies and case reports [9]. The continuous effort to develop advanced techniques at higher resolution has led to a more common application of virtual autopsy (virtopsy) in medical examiners' offices nowadays $[17,18]$. This trend not only resulted in a plentiful production of articles to validate the utility of CT compared to traditional autopsy or other types of imaging techniques, e.g., [19-21], but also expanded the applicability of CT (e.g., estimation of pupae's developmental age [22]; reconstruction of bloodstain in fabric [23]; determination of non-human skeletal remains [24]). Recently, the need to establish new and efficient processing protocols has increased in the field where CT is applied, e.g., [25]. In the field of forensic anthropology, the CT technique has been introduced relatively recently as shown in the keyword analysis (Figure 5); however, the number of forensic anthropological studies using CT has increased rapidly. Particularly, there has been increasing efforts to develop new models for sex and age estimation using CT, e.g., [26-28], to validate the accuracy of osteometric measurements in the CT scans, e.g., [29,30], and to automate the analysis processes where CT is involved, e.g., [31,32]. In addition, Cone Beam CT has been frequently used to measure the thickness of facial soft tissues and contributed to the field of facial reconstruction and personal identification, e.g., [31,33].

As to the application of VOSviewer for a bibliometric analysis, Demir et al. [6] pointed out two limitations which the current study could also not avoid: a risk of self-citation and a risk of excluding publications written in a non-English language from the analyses. In addition, since the scope of publications analyzed by VOSviewer is determined primarily by the keywords entered during the Document Search process, there is a possibility that a bibliometric study may not include all publications of a targeted field. To avoid this issue, a careful selection of keywords will be required. In this regard, this study used four keywords ("forensic", "legal medicine", "medicolegal", and "computed tomography") to include as many related publications as possible. Lastly, some information presented by VOSviewer may slightly differ from what they actually are because VOSviewer analyzes data as the authors of the original publications literally provided. For example, if an author working in a university hospital used the names of the university and the hospital in two different papers as his/her affiliation, there is no way for VOS viewer to notice it. A careful inspection and verification of the information as well as an effort to avoid these limitations will be necessary in the future research.

\section{Conclusions}

The use of CT in the forensic context has increased drastically since the early 2000s, which caused the plentiful production of articles. This increasing trend appears to continue as more researchers and institutions include the CT technique in their works and research. At the same time, the scope of CT-related research will likely expand to more diverse subfields of forensic science, which will result in a fruitful production of publications with a variety of topics. In this regard, the current study will be particularly helpful to the researchers who have recently initiated CT-related research by providing them with a holistic insight into the research trend as well as a source of potential collaborations (i.e., productive countries, institutions and authors).

Author Contributions: Conceptualization, Y.J. and E.J.W.; methodology, Y.J.; software, Y.J.; validation, E.J.W. and S.L.; formal analysis, Y.J.; investigation, Y.J. and E.J.W.; resources, E.J.W. and S.L.; data curation, Y.J.; writing-original draft preparation, Y.J. and E.J.W.; writing-review and editing, S.L.; visualization, Y.J.; supervision, E.J.W.; project administration, Y.J. and E.J.W.; funding acquisition, Y.J., E.J.W. and S.L. All authors have read and agreed to the published version of the manuscript.

Funding: This research was funded by the National Forensic Service (NFS2020MED06), Ministry of the Interior and Safety, Republic of Korea, and the National Research Foundation of Korea (2018R1A5A7023490), Ministry of Science and ICT, Republic of Korea.

Acknowledgments: The authors are sincerely grateful to Sophia Lee and anonymous reviewers for providing valuable comments and reviewing the manuscripts. 
Conflicts of Interest: The authors declare no conflict of interest.

\section{References}

1. Brodgon, B.G.; Lichtenstein, J.E. Forensic radiology in historical perspective. In Forensic Radiology, 2nd ed.; Thali, M.J., Viner, M.D., Brogdon, B.G., Eds.; CRC Press: Boca Raton, FL, USA, 2011; pp. 9-24.

2. Rutty, G.N. Are invasive autopsies necessary? Forensic Sci. Med. Pathol. 2005, 1, 71-73. [CrossRef]

3. Uhrenholt, L.; Boel, L.W.T. Contribution from forensic imaging to the investigation of upper cervical fractures. J. Forensic Sci. 2010, 55, 1598-1602. [CrossRef]

4. Thali, M.J.; Schweitzer, W.; Yen, K.; Vock, P.; Ozdoba, C.; Spielvogel, E.; Dirnhofer, R. New horizons in forensic radiology: The 60-second digital autopsy-full-body examination of a gunshot victim by multislice computed tomography. Am. J. Forensic Med. Pathol. 2003, 24, 22-27. [CrossRef] [PubMed]

5. Obertová, Z.; Leipner, A.; Messina, C.; Vanzulli, A.; Fliss, B.; Cattaneo, C.; Sconfienza, L.M. Postmortem imaging of perimortem skeletal trauma. Forensic Sci. Int. 2019, 109921. [CrossRef] [PubMed]

6. Demir, E.; Yaşar, E.; Özkoçak, V.; Yıldırım, E. The evolution of the field of legal medicine: A holistic investigation of global outputs with bibliometric analysis. J. Forensic Leg. Med. 2020, 69, 101885. [CrossRef] [PubMed]

7. Shi, G.; Liu, N.; Yu, X.; Zhang, H.; Li, S.; Wu, S.; Wang, W.; Huang, P.; Li, C. Bibliometric analysis of medical malpractice literature in legal medicine from 1975 to 2018: Web of Science review. J. Forensic Leg. Med. 2019, 66, 167-183. [CrossRef] [PubMed]

8. Scopus. Available online: https://www-scopus-com.ezproxy.mtsu.edu/search/form.uri?display=basic/ (accessed on 29 September 2020).

9. Ostertag, C.B.; Sternsdorff, H.W.; Joachim, H. Diagnostic possibities for computed tomography in forensic examination of persons with cerebral trauma. Z. Fuer Rechtsmed. 1978, 82, 137-143. [CrossRef] [PubMed]

10. Kumar, S.R.; Kaliyaperumal, K. A scientometric analysis of mobile technology publications. Scientometrics 2015, 105, 921-939. [CrossRef]

11. VOSviewer 1.6.15. Available online: https://www.vosviewer.com/ (accessed on 5 July 2020).

12. van Eck, N.J.; Waltman, L. Software survey: VOSviewer, a computer program for bibliometric mapping. Scientometrics 2010, 84, 523-538. [CrossRef]

13. Boscolo-Berto, R.; Viel, G.; Cecchi, R.; Terranova, C.; Vogliardi, S.; Bajanowski, T.; Ferrara, S.D. Journals publishing bio-medicolegal research in Europe. Int. J. Legal Med. 2012, 126, 129-137. [CrossRef]

14. Viel, G.; Boscolo-Berto, R.; Cecchi, R.; Bajanowski, T.; Vieira, N.D.; Ferrara, S.D. Bio-medicolegal scientific research in Europe: A country-based analysis. Int. J. Legal Med. 2011, 125, 717-725. [CrossRef] [PubMed]

15. Ozsoy, Z.; Demir, E. The evolution of bariatric Surgery publications and global productivity: A bibliometric analysis. Obes. Surg. 2018, 28, 1117-1129. [CrossRef] [PubMed]

16. Gualdi-Russo, E.; Fonti, G. Recent trend and perspectives in forensic anthropology: A bibliometric analysis. Coll. Antropol. 2013, 37, 595-599. [PubMed]

17. Timonov, P.; Novakov, S.; Sivkov, S.; Fasova, A.; Novakov, I.; Spasov, S. The advantage of the virtual forensic autopsy-A new approach which could benefit forensic expertise. J. Forensic Leg. Med. 2019, 62, 69-71. [CrossRef] [PubMed]

18. Leth, P.M. Virtual autopsy. Forensic Sci. Med. Pathol. 2013, 9, 432. [CrossRef] [PubMed]

19. Willaume, T.; Farrugia, A.; Kieffer, E.; Charton, J.; Geraut, A.; Berthelon, L.; Gierry, G.; Raul, J. The benefits and pitfalls of post-mortem computed tomography in forensic external examination: A retrospective study of 145 cases. Forensic Sci. Int. 2018, 286, 70-80. [CrossRef] [PubMed]

20. Mishima, S.; Suzuki, H.; Fukunaga, T.; Nishtani, Y. Postmortem computed tomography findings in cases of bath-related death: Applicability and limitation in forensic practice. Forensic Sci. Int. 2018, 282, 195-203. [CrossRef] [PubMed]

21. Filograna, L.; Tartaglione, T.; Filograna, E.; Cittadini, F.; Oliva, A.; Pascali, V.L. Computed tomography (CT) virtual autopsy and classical autopsy discrepancies: Radiologist's error or a demonstration of post-mortem multi-detector computed tomography (MDCT) limitation? Forensic Sci. Int. 2010, 195, e13-e17. [CrossRef] [PubMed] 
22. Richards, C.S.; Simonsen, T.J.; Abel, R.L.; Hall, M.J.R.; Schwyn, D.A.; Wicklein, M. Virtual forensic entomology: Improving estimates of minimum post-mortem interval with 3D micro-computed tomography. Forensic Sci. Int. 2012, 220, 251-264. [CrossRef]

23. Dicken, L.; Knock, C.; Carr, D.J.; Beckett, S. The effect of fabric mass per unit area and blood impact velocity on bloodstain morphology. Forensic Sci. Int. 2019, 301, 12-27. [CrossRef]

24. Lucena, J.; Mora, E.; Rodriguez, L.; Muňoz, M.; Cantin, M.G.; Fonseca, G.M. Cone beam computed tomography (CBCT) as a tool for the analysis of nonhuman skeletal remains in a medico-legal setting. Forensic Sci. Int. 2016, 266, e32-e37. [CrossRef] [PubMed]

25. Stock, M.K.; Garvin, H.M.; Corron, L.K.; Hulse, C.N.; Cirillo, L.E.; Klales, A.R.; Colman, K.L.; Stull, K.E. The importance of processing procedures and threshold values in CT scan segmentation of skeletal elements: An example using the immature os coxa. Forensic Sci. Int. 2020, 309, 110232. [CrossRef] [PubMed]

26. Feld, K.; Bonni, M.; Körber, F.; Eifinger, F.; Banaschak, S. Post-mortem estimation of gestational age and maturation of new-borns by CT examination of clavicle length, femoral length and femoral bone nuclei. Forensic Sci. Int. 2020, 314, 110391. [CrossRef]

27. Franchi, A.; Valette, S.; Agier, R.; Prost, R.; Kéchichan, R.; Fanton, L. The prospects for application of computational anatomy in forensic anthropology for sex determination. Forensic Sci. Int. 2019, 297, 156-160. [CrossRef] [PubMed]

28. Ford, J.M.; Kumm, T.R.; Decker, S. An analysis of Hounsfield unit values and volumetrics from computerized tomography of the proximal femur for sex and age estimation. J. Forensic Sci. 2020, 65, 591-596. [CrossRef]

29. Mohamed, M.M.A.; Ahmed, H.M.; Hassan, O.A.; Abdelwahab, M.A.; Younis, R.H.A. Reliability of internal metacarpal measurements for sex determination using multi-detector computed tomographic imaging in a sample of Egyptian population. Aust. J. Forensic Sci. 2020. [CrossRef]

30. Ismail, N.A.; Abdullah, N.; Noor, M.H.M.; Lai, P.S.; Shafie, M.S.; Nor, F.M. Accuracy and reliability of virtual femur measurement from CT scan. J. Forensic Leg. Med. 2019, 63, 11-17. [CrossRef] [PubMed]

31. Ridel, A.F.; Demeter, F.; Galland, M.; L'abbé, E.N.; Vandermeulen, D.; Oettlé, A.C. Automatic landmarking as a convenient prerequisite for geometric morphometrics; Validation on cone beam computed tomography (CBCT)-based shape analysis of the nasal complex. Forensic Sci. Int. 2020, 306, 110095. [CrossRef]

32. de Souza, L.A., Jr.; Marana, A.N.; Weber, S.A.T. Automated frontal sinus recognition in computed tomography images for person identification. Forensic Sci. Int. 2018, 286, 252-264. [CrossRef]

33. Thitiorul, S.; Mahakkanukrauh, P.; Prasitwattanaseree, S.; Sitthiseripratip, K.; Iamaroon, A.; Lampang, S.N.; Prapayasatok, S. Three-dimensional prediction of the nose for facial approximation in a Thai population. J. Forensic Sci. 2019, 65. [CrossRef]

Publisher's Note: MDPI stays neutral with regard to jurisdictional claims in published maps and institutional affiliations.

(C) 2020 by the authors. Licensee MDPI, Basel, Switzerland. This article is an open access article distributed under the terms and conditions of the Creative Commons Attribution (CC BY) license (http://creativecommons.org/licenses/by/4.0/). 